\title{
EFFECTS OF SHORT- AND LONG-TERM GLUCAN FEEDING OF RAINBOW TROUT (SALMONIDAE) ON THE SUSCEPTIBILITY TO ICHTHYOPHTHIRIUS MULTIFILIIS INFECTIONS
}

\author{
Jesper H. LAURIDSEN and Kurt BUCHMANN* \\ Department of Veterinary Disease Biology, University of Copenhagen \\ Faculty of Life Sciences, Frederiksberg C, Denmark
}

Lauridsen J.H., Buchmann K. 2010. Effects of short- and long-term glucan feeding of rainbow trout (Salmonidae) on the susceptibility to Ichthyophthirius multifiliis infections. Acta Ichthyol. Piscat. 40 (1): 61-66.

\begin{abstract}
Background. Various compounds are being used as immuno-stimulants in various aquaculture feed types but the importance of their prolonged use is at present unknown. It is also true for those intended to modify trout susceptibility to white spot disease caused by Ichthyophthirius multifiliis. The immuno-modulating effects on rainbow trout of short- and long-term feeding using dry feed with inclusion of beta-glucan $(0.2 \%)$ have therefore been evaluated.

Materials and Methods. The immune reactivity was assessed by measuring susceptibility to I. multifiliis infections and plasma lysozyme in the host, factors which are considered innate response parameters. Rainbow trout, Oncorhynchus mykiss (Walbaum, 1792) (Actinopterygii: Salmoniformes: Salmonidae), were fed (control feed or glucan-containing feed) for 14 or 35 days before challenge (exposure to infective I. multifiliis theronts) and the resulting infection (number of trophonts in the skin) was recorded on day 11 post-exposure to theronts.

Results. All fish obtained infection following parasite exposure but glucan-fed fish showed a lower infection at day 46 compared to fish fed control-feed. The lysozyme activity of fish plasma was evaluated throughout the experimental period and found slightly but significantly increased in association with glucan-feeding at day 14, 17 , and 46.

Conclusion. No evidence for an exhaustion of these selected innate response parameters due to prolonged glucan-feeding could be detected within the experimental period of 46 days.
\end{abstract}

Keywords: Rainbow trout, white spot disease, ich, Ichthyophthirius multifiliis, beta-glucan, immunostimulants, immunity

\section{INTRODUCTION}

Various compounds are being applied as feed additives for fish based on their suggested role as immunostimulants (de Baulny et al. 1996, Cook et al. 2003, Bagni et al. 2005, Pieters et al. 2008). The structural carbohydrate beta-glucan is one of these products and it is known to activate innate immune mechanisms of various animals including fish (Paulsen et al. 2001, 2003, Bricknell and Dalmo 2005, Misra et al. 2006, Skjermo et al. 2006). It can be argued that prolonged use of these immunostimulants may exhaust the responsiveness of fish and that feeding should be restricted to a short period (Bricknell and Dalmo 2005). In fact, in vitro studies have demonstrated that macrophages elicit a respiratory burst following beta-glucan exposure but also that the response of isolated cells is immediate and fades after prolonged stimulation (Chettri et al. 2010). However, feeding sea bass with glucan-supplemented feed $(0.1 \%)$ for extended periods did not result in decreased responsiveness of fish (Bagni et al. 2000, 2005). Neither did long term administration of low dosages $(0.01 \%-0.05 \%)$ to rohu carp (Labeo rohita) lead to a decrease of the resistance to challenge infections using Aeromonas hydrophila and Edwarsiella tarda (see Misra et al. 2006). However, the possible exhaustion of the host response due to prolonged stimulation is important to address in practical aquaculture where glucans are widely applied in fish feed. Likewise, effects of these immuno-stimulants may vary between different host-pathogen systems. The skin-parasitic ciliate I. multifiliis causing white spot disease is one of the major pathogens in freshwater fish (Hines and Spira 1974, Matthews 2005). Also rainbow trout farming suffers from this disease but no information is at present available with regard to the effect of glucans on the rainbow trout

\footnotetext{
${ }^{*}$ Correspondence: Prof. Kurt Buchmann, Department of Veterinary Disease Biology, Section of Biomedicine, Faculty of Life Sciences, Stigbøjlen 7, Frederiksberg C, Denmark, phone.: +45-35282700, fax: +45-35282755, e-mail: kub@life.ku.dk
} 
response against this parasite. Our knowledge of the influence of beta-glucans on innate immune parameters in rainbow trout skin following short- and long-term beta-glucan feeding is similarly limited. Although the response in fish against skin parasites can involve adaptive factors (Clark and Dickerson 1997, Dickerson and Clark 1998, Sigh and Buchmann 2001, Xu et al. 2006) immunity in rainbow trout is at least partly based on innate factors (Buchmann et al. 1999, Fast et al. 2002, Pieters et al. 2008). Thus, a series of studies have indicated that specific antibodies may confer immunity in channel catfish and rainbow trout against this skin parasitizing ciliate. However, it has also been noted that responses against gyrodactylids confer some cross-protection against white spot disease in rainbow trout (Buchmann et al. 1999) which suggests that innate response mechanisms take part in this protection. In addition, probiotics may have a similar effect (Pieters et al 2008). Therefore, this parasite-host system is an appropriate model for testing these topics. The present study was undertaken in order to evaluate the effects of glucan on innate responsiveness in rainbow trout over time by performing a feeding experiment and exposing fish to I. multifiliis following 14 and 35 days feeding with control or glucan-containing feed. In addition the plasma lysozyme activity (an indicator of innate immune reactivity) of the fish was measured throughout the period.

\section{MATERIALS AND METHODS}

Fish. Rainbow trout (Oncorhynchus mykiss) were obtained from The Danish Centre for Wild Salmon in Randers where they had been hatched and reared under pathogen-free conditions at $12^{\circ} \mathrm{C}$ in municipal tap water. They were then brought to the experimental facilities at the University of Copenhagen. Prior to the experimental feeding fish were acclimated in two recirculated $200 \mathrm{~L}$ tanks at $13^{\circ} \mathrm{C}$ for 4 weeks under a constant $12: 12 \mathrm{~h}$ light-dark cycle. The fish were, before the experimental start, fed with control pelleted trout feed (Biomar, Denmark) at the rate of $1 \%$ of the biomass per day. Water was replenished daily and concentrations of nitrite, nitrate, ammonia, and $\mathrm{pH}$-levels were measured on a regular basis (Merck Aquacant, Germany).

Experimental fish feed. Control feed was $3 \mathrm{~mm}$ pelleted dry feed based on fish-meal and fish oil (protein $46 \%$, fat $28 \%$, carbohydrate $16 \%$, and ash $7 \%$ ) and the experimental feed was similarly composed but enriched with $0.2 \% \beta$-glucan from yeast, Saccharomyces cerevisiae (Biomar A/S Brande, Denmark).

Parasite culture. A laboratory culture of I. multifiliis obtained from a Danish fish farm (Refsgaard Fish farm) was established. The parasite population was maintained in laboratory aquaria through serial passage to naive rainbow trout at $13^{\circ} \mathrm{C}$ for six months before experimental start.

Isolation of infective theronts (for challenge infection). Highly infected fish were killed using an overdose (200 mg $\cdot \mathrm{L}^{-1}$ ) of MS-222 (Sigma-Aldrich, Denmark) and placed in a small water-filled container (water volume $1000 \mathrm{~mL}$ ). Within $30 \mathrm{~min}$ trophonts escaped the fish epi- dermis and transformed into tomocysts. After $24 \mathrm{~h}$ at room temperature $\left(20-22^{\circ} \mathrm{C}\right)$, infective theronts appeared in the water. The number of viable theronts was determined with a $1 \mathrm{~mL}$ Sedgewick-Rafter counting chamber and subsequently used for challenge. Viability of theronts was assessed by their movements.

Parasite challenge. Five fish from each of the two groups were exposed to a total of 5000 theronts in a 125 L fish tank (1000 theronts per fish) on day 14 and 35 after start of the experimental feeding.

Counting trophonts in fish skin following parasite exposure. Following challenge the five fish in the sample were anaesthetised (on day 11 post-exposure) in $60 \mathrm{mg} \cdot \mathrm{L}^{-1}$ MS222 (Sigma-Aldrich, Denmark) and examined under a dissection microscope (7-50× magnification) whereby the total number of visible trophonts were enumerated (fins and body skin). Five control fish were examined similarly.

Experimental design. The experimental design included a total of 90 fish with a body weight of 18-20 g. The fish were kept in two fish tanks (water volume $200 \mathrm{~L}$, recirculated with bio-filters (Eheim, Germany) each with 45 fish. The groups were fed daily (1\% of biomass per day) with experimental feed containing beta-glucan or control feed without any additive. This feeding rate was used also after parasite exposure.

Fish ( 5 per sample) were taken from the tanks on day 14 and 35 and then exposed, in separate fish tanks, to a total of approximately 1000 infective theronts per fish. Thus, a total of 10 fish were exposed at these two timepoints. The infection was then followed for 11 days postexposure. Blood samples for lysozyme analysis were taken from five fish from each group (experimental and control) on day $14,17,21,25,38,42$, and 46 . Thus, a total of ten fish were blood-sampled at each time point whereafter they were euthanized and taken out of the experiment.

Blood sampling. Blood for plasma lysozyme measurement was taken from anaesthetized fish $\left(60 \mathrm{mg} \cdot \mathrm{L}^{-1} \mathrm{MS}-222\right)$ by caudal vein puncture using heparinised syringes $(1 \mathrm{~mL})$ (five fish per sample). The blood was centrifuged $(5000 \times g)$ and the plasma was isolated and frozen at $-20^{\circ} \mathrm{C}$ until use performing the lysozyme assay. Fish were removed from the experiment following sampling.

Plasma lysozyme activity. Lysozyme activity was measured using the agarose diffusion assay because this technique has proven relevant in previous studies by Alishahi and Buchmann (2006). Therefore, turbidometric assays (based on absorbance) were not used. Therefore, lysozyme activity was measured according to Lie et al. (1986). Briefly, $20 \mathrm{~mL} \mathrm{1 \%} \mathrm{agarose} \mathrm{solution} \mathrm{prepared} \mathrm{with}$ $0.1 \mathrm{M}$ phosphate buffer ( $\mathrm{pH}$ 6.6) containing Micrococcus lysodeikticus $\left(50 \mu \mathrm{g} \cdot \mathrm{L}^{-1}\right)$ (Sigma-Aldrich, Denmark) was poured onto a $10 \times 10 \mathrm{~cm}$ glass plate and allowed to solidify. Wells (diameter $4 \mathrm{~mm}$ ) were punched into the agarose layer and diluted (1:10 in phosphate buffered saline PBS) plasma-samples $(10 \mu \mathrm{L})$ from rainbow trout were subsequently placed in the wells. For reference a dilution series of chicken lysozyme (Sigma-Aldrich, Denmark) 
was prepared and different concentrations of lysozyme were applied likewise. Samples on the agarose-covered glass plates were incubated for $20 \mathrm{~h}$ at $20^{\circ} \mathrm{C}$, pressed under filter paper and air-dried. Following the drying process, plates were Gram-stained with methyl-violet for $1 \mathrm{~min}$, post-fixed in Lugol's solution for $15 \mathrm{~s}$, and finally de-stained with ethanol $(96 \%)$ until clear zones were detectable. Diameters were measured $(\mathrm{mm})$ and used for estimation of lysozyme activity in plasma samples based on a standard curve constructed from the association between chicken lysozyme activity and diameters of lysed zones.

Statistical analysis. The mean of parasite numbers on fish in different control and experimental groups were compared using the Mann-Whitney U-test. Lysozyme activity in plasma from different fish groups were analysed using the Student's $t$-test. A 5\% probability level was applied in all tests.

The experiments were performed under the approval of the committee for animal experimentation, The Danish Ministry of Justice, Copenhagen, Denmark.

\section{RESULTS}

Trophonts. Fish fed the $\beta$-glucan feed became infected with slightly fewer detectable trophonts than those fed the standard feed. This was seen both after 14 and 35 days feeding but the difference was only statistically significant after 35 days as judged from counting at day 46 (11 days post-exposure) (Table 1).

Lysozyme assay. A general trend for a slightly higher activity of lysozyme was found in plasma from fish in the glucan-fed group compared to the control group (significant differences on days 14, 17, and 46). Further, a slight increase of this parameter was seen in the glucan-fed fish throughout the experimental period whereas no consistent trend was found in the control fish (Table 2).

\section{DISCUSSION}

The susceptibility of fish to infection with I. multifiliis is dependent on a number of factors comprising both innate and adaptive elements (Buchmann et al. 2001, Matthews 2005). It is therefore appropriate to use this skin ciliate infection model to evaluate activation of innate antiparasitic responses in trout evoked by beta-glucan feeding.

A slight but significant protection (expressed as a decrease in the number of skin trophonts) against infection following glucan-feeding was indicated following 46 days. A weak and non-statistically significant effect was seen at day 25. This recorded skin response, which was marginal, may not be satisfactory for practical fish-culture purposes. However, it is noteworthy that glucans could stimulate the skin and the results supports the notion that glucans in fish have general immunomodulating effects as previously indicated by several authors (de Baulny et al. 1996, Strand and Dalmo 1997, Bagni et al. 2005, Bricknell and Dalmo 2005, Misra et al. 2006, Selvaraj et al. 2006, Ai et al. 2007).

The intestinal epithelium in larvae of Atlantic halibut (Hippoglossus hippoglossus) has been shown to be involved in the glucan-uptake (Strand and Dalmo 1997) and a similar mechanism may exist in rainbow trout. Once in the bloodstream or lymph, different receptors on a range of leucocytes are able to bind the glucan molecules (Czop 1986, Chettri et al. 2010). Dectin-1 is a transmembrane lectin-like receptor that has been identified on the surface of macrophages, dendritic cells, neutrophils, and certain T-cells in various mammals (Ariizumi et al. 2000, Taylor et al. 2002, Brown 2006) but not in fish. Briefly, the receptor, known as a pattern-recognition receptor (PRR), is able to recognize and bind a distinct part of the $\beta$-glucan molecule. The part of the glucan molecule bound to the receptor is known as a pathogen-associatedmolecular-pattern (PAMP). Once the $\beta$-glucan molecule has been bound, the receptor will initiate an intracellular signalling cascade, which ultimately may lead to the release of cytokines and chemokines such as TNF- $\alpha$, IL$1 \beta$, IL-6, IL-8, IL-10 and IL-12. (Brown et al. 2003, Gantner et al. 2003, Brown 2006). Furthermore, the binding may also induce phagocytosis and a subsequent respiratory burst (Czop 1986, Herre et al. 2004). A dectin-1 homologue has not yet been found in fish but a complement receptor in carp is known to bind $\beta$-glucans (Nakao et al. 2003) which could explain glucan effects in fish.

One of the innate functional molecules produced by rainbow trout upon immunization against $I$. multifiliis is plasma lysozyme (Alishahi and Buchmann 2006). This factor, which also has strong antibacterial effects, was analysed in the present feeding experiment. It was seen that the lysozyme activity increased slightly (with an exception at day 25) throughout the experimental period in glucan-fed fish in which the activity was significantly elevated at day 14,17 , and 46 . In contrast, control fish plasma showed in most cases a lower activity with irregular variations during the same period. A lysozyme up- regulation following $\beta$-glucan treatment has previously been seen in vivo in Atlantic salmon (Paulsen et al. 2001, 2003), sea bass (Bagni et al. 2005), and in rohu carp (Misra et al. 2006). The slightly higher lysozyme level in glucan-fed fish found in

Mean number $( \pm \mathrm{SD})$ of parasites per fish at day 11 post-exposure in fish fed beta-glucan

Table 1 for 14 and 35 days before exposure

\begin{tabular}{lcc}
\hline Time fed before exposure [days] & Control feed & Glucan feed \\
\hline 14 & $26.2 \pm 9.5$ & $22.4 \pm 5.9$ \\
35 & $32.8 \pm 5.9$ & $26.8 \pm 6.8^{*}$ \\
\hline
\end{tabular}

*significantly different from control; $P<0.05$ (Mann-Whitney U-test). 
Lysozyme activity of rainbow trout fed control feed and glucan-feed; Mean diameters $(\mathrm{mm})( \pm \mathrm{SD})$ of clear zones and corresponding lysozyme activity $\left(\mu \mathrm{g} \cdot \mathrm{mL}^{-1}\right)$

(SD) of chicken egg white lysozyme; Five fish in each sample

\begin{tabular}{lcccc}
\hline \multirow{2}{*}{$\begin{array}{l}\text { Feeding time } \\
\text { [days] }\end{array}$} & \multicolumn{2}{c}{ Control feed } & \multicolumn{2}{c}{ Glucan feed } \\
\cline { 2 - 5 } & clear zone diameter & lysozyme activity & clear zone diameter & lysozyme activity \\
\hline 14 & $8.8 \pm 1.8$ & $1.88 \pm 6.2$ & $10.6 \pm 4.5^{*}$ & $4.59 \pm 9.5$ \\
17 & $8.0 \pm 1.8$ & $1.27 \pm 4.2$ & $10.0 \pm 1.4^{*}$ & $3.41 \pm 4.3$ \\
21 & $10.6 \pm 2.7$ & $4.59 \pm 4.1$ & $11.6 \pm 1.7$ & $7.53 \pm 5.1$ \\
25 & $10.4 \pm 2.61$ & $4.16 \pm 5.1$ & $8.8 \pm 1.5$ & $1.88 \pm 4.5$ \\
38 & $12.6 \pm 1.7$ & $12.36 \pm 5.3$ & $11.6 \pm 1.8$ & $7.53 \pm 4.9$ \\
42 & $11.2 \pm 1.1$ & $6.18 \pm 6.2$ & $11.0 \pm 2.0$ & $5.60 \pm 5.1$ \\
46 & $9.0 \pm 1.6$ & $2.08 \pm 6.0$ & $13.6 \pm 1.1^{*}$ & $20.27 \pm 5.3$ \\
\hline
\end{tabular}

* significantly different from control; $P<0.05$ (Student's $t$-test).

our study was associated with a lower infection level at day 46. No causative relations between a low lysozyme activity and higher susceptibility to the parasite have been proved in this or other studies but both factors reflect a level of innate reactivity in the host. It is therefore noteworthy that prolonged (46 days) feeding did not cause an exhaustion of the response when compared to a short (14 days) feeding period.

It is generally accepted that glucan-preparations can differ (Manners et al. 1974) and the effect of $\beta$-glucans is related to dosage (Ai et al. 2007), physico-chemical properties such as backbone/branch configuration (Seviour et al. 1992), solubility (Xiao et al. 2004), and molecular weight (Falch et al. 2000). Further, the optimal type and dosage of $\beta$-glucan varies between different diseases (Chen and Seviour 2007), which makes it very difficult to generalize about administrative strategies. However, the present study showed that a basic trout feed type with a $0.2 \%$ inclusion of beta-glucan from yeast ( $S$. cerevisiae) was associated with a slight lysozyme increase in plasma (at day 14, 17, and 46) and with an elevated resistance to I. multifiliis infections at day 46 . Yeast derived $\beta$-glucans consist of a backbone of glucose residues linked by $\beta$ $(1 \rightarrow 3)$ glycosidic bonds. These polysaccharides are important structural elements in the cell wall of many yeast and myceloid fungi where they constitute up to sixty percent of the cell mass (Seviour et al. 1992). Most $\beta$-glucans used for experiments on immuno-stimulation are $\beta$ $(1 \rightarrow 3)(1 \rightarrow 6)$-glucans extracted from the cell walls of various fungi, although positive effects of $\beta-(1 \rightarrow 4)(1 \rightarrow 6)$ glucans from grasses such as barley and wheat also have been described (Sealey et al. 2007). Other described sources of $\beta$-glucans are lichens, bacteria, diatoms and algae (Skjermo et al. 2006). The glucans can be either soluble or particulate depending on their degree of polymerization (Zeković et al. 2005) and both soluble and insoluble (particulate) $\beta$-glucans show immunomodulatory effects although insoluble glucans tend to have higher effect (Cleary et al. 1999, Selvaraj et al. 2005).

It is generally believed that a prolonged stimulation of the immune system can exhaust the responsiveness. This was also indicated for rainbow trout macrophages stimu- lated in vitro by beta-glucans (Chettri et al. 2010) and is being considered in various types of aquaculture (Bricknell and Dalmo 2005). However, the suggested exhaustion of the host response following prolonged stimulation with a low dose $(0.2 \%)$ in feed does not seem to apply in the present in vivo feeding study of rainbow trout but it does not exclude that exhaustion can occur under other conditions. Therefore, experiments should be conducted in order to investigate the importance of other glucan-types (origin and particulation), other glucan-concentrations and even longer feeding periods.

\section{ACKNOWLEDGEMENTS}

This work was supported by the European Community through a grant under FP6 to the project Improved Immunity of Aquacultured Animals IMAQUANIM and by the Danish Ministry for Food, Agriculture and Fisheries (Strategies to improve HEALTH AND WELFARE in rainbow trout farming FFS95-7).

\section{REFERENCES}

Ai Q., Mai K., Zhang L., Tan B., Zhang W., Xu W., Li H. 2007. Effects of dietary $\beta-1,3$ glucan on innate immune response of large yellow croaker, Pseudosciaena crocea. Fish and Shellfish Immunology 22 (4): 394-402. DOI: 10.1016/j.fsi.2006.06.011.

Alishahi M., Buchmann K. 2006. Temperature-dependent protection against Ichthyophthirus multifiliis following immunisation of rainbow trout using live theronts. Diseases of Aquatic Organisms 72 (3): 269-273.

DOI: $10.3354 /$ dao0 072269 .

Ariizumi K., Shen G.-L., Shikano S., Xu S., Ritter R. 3rd , Kumamoto T., Edelbaum D., Morita A., Bergstresser P.R., Takashima A. 2000. Identification of a novel, dendritic cell-associated molecule, dectin-1, by subtractive cDNA cloning. Journal of Biological Chemistry 275 (26): 20157-20167. DOI: 10.1074/jbc.M909512199.

Bagni M., Archetti L., Amadori M., Marin, G. 2000. Effect of long-term oral administration of an immunostimulant diet on innate immunity in sea bass (Dicentrarchus labrax). Journal of Veterinary Medicine B 47 (10): 745-751. DOI: 10.1111/j.1439-0450.2000.00412.x. 
Bagni M., Romano N., Finoia M.G., Abelli L., Scapigliati G., Tiscar P.G., Sarti M., Marino G. 2005. Short- and longterm effects of a dietary yeast $\beta$-glucan (Macrogard) and alginic acid (Ergosan) preparation on immune response in sea bass (Dicentrarchus labrax). Fish and Shellfish Immunology 18 (4): 311-325. DOI: 10.1016/j.fsi.2004.08.003.

Bricknell I., Dalmo R.A. 2005. The use of immunostimulants in fish larval aquaculture. Fish and Shellfish Immunology 19 (5): 457-472. DOI: 10.1016/j.fsi.2005.03.008.

Brown G.D. 2006. Dectin-1: a signalling non-TLR patternrecognition receptor. Nature Reviews Immunology 6: 33-43. DOI: 10.1038/nri1745.

Brown G.D., Herre J., Williams D.L., Willment J.A., Marshall A.S.J., Gordon S. 2003. Dectin-1 mediates the biological effects of $\beta$-glucans. The Journal of Experimental Medicine 197 (9): 1119-1124.

DOI: $10.1084 /$ jem.20021890.

Buchmann K., Lindenstrøm T., Sigh J. 1999. Partial cross protection against Ichthyophthirius multifiliis in Gyrodactylus derjavini immunized rainbow trout. Journal of Helminthology 73 (3): 189-195. DOI: 10.1017/S0022149X9900030X.

Buchmann K., Sigh J., Nielsen C.V., Dalgaard M. 2001. Host responses against the fish parasitizing ciliate Ichthyophthirius multifiliis. Veterinary Parasitology 100: 105-116.

Chen J., Seviour R. 2007. Medicinal importance of fungal $\beta-(1 \rightarrow 3),(1 \rightarrow 6)$-glucans. Mycological Research 111 (6): 632-652. DOI: 10.1016/j.mycres.2007.02.011.

Chettri J.K.C., Holten-Andersen L., Buchmann K. 2010. Factors influencing in vitro respiratory burst assays with head kidney leukocytes from rainbow trout, Oncorhynchus mykiss (Walbaum). Journal of Fish Diseases. (In press.) DOI: $10.1111 / j .1365-2761.2010 .01160 . x$

Clark T.G., Dickerson H.W. 1997. Antibody-mediated effects on parasite behavior: Evidence of a novel mechanism of immunity against a parasitic protist. Parasitology Today 13 (12): 477-480.

Cleary J.L. Kelly G.E., Husband A.J. 1999. The effect of molecular weight and $\beta$-1,6-linkages on priming of macrophage function in mice by $(1,3)-\beta$-D-glucan. Immunology and Cell Biology 77 (5): 395-403. DOI: 10.1046/j.1440-1711.1999.00848.x.

Cook M.T., Hayball P.J., Hutchinson W., Nowak B.F., Hayball J.D. 2003. Administration of a commercial immunostimulant preparation, EcoActiva ${ }^{\mathrm{TM}}$ as a feed supplement enhances macrophage respiratory burst and the growth rate of snapper (Pagrus auratus, Sparidae (Bloch and Schneider)) in winter. Fish and Shellfish Immunology 14 (4): 333-345. DOI: 10.1006/fsim.2002.0441.

Czop J.K. 1986. The role of $\beta$-glucan receptors on blood and tissue leukocytes in phagocytosis and metabolic activation. Pathology and Immunopathology Research 5 (3-5): 286-296. DOI: 10.1159/000157022.

de Baulny M.O., Quentel C., Fournier V., Lamour F., Le Gouvello R. 1996. Effect of long-term oral administration of $\beta$-glucan as an immunostimulant or an adjuvant on some non-specific parameters of the immune response of turbor Scophthalmus maximus. Diseases of Aquatic Organisms 26 (2): 139-147. DOI: 10.3354/dao026139.
Dickerson H.W., Clark T.G. 1998. Ichthyophthirius multifiliis: a model of cutaneous infection and immunity in fishes. Immunological Reviews 166 (1): 377-384.

Falch B.H., Espevik T., Ryan L., Stokke B.T. 2000. The cytokine stimulating activity of $(1 \rightarrow 3)-\beta-{ }^{\mathrm{D}}$-glucans is dependent on the triple helix conformation. Carbohydrate Research 329 (3): 587-596. DOI: 10.1016/s0008-6215(00)00222-6.

Fast M.D., Simsa D.E., Burka J.F., Mustafa A., Ross N.W. 2002. Skin morphology and humoral non-specific defence parameters of mucus and plasma in rainbow trout, coho and Atlantic salmon. Journal of Comparative Biochemistry and Physiology Part A 132 (3): 645-657.

Gantner B.N., Simmons R.M., Canavera S.J., Akira S., Underhill D.M. 2003. Collaborative induction of inflammatory responses by dectin-1 and toll-like receptor 2. Journal of Experimental Medicine 197 (9): 1107-1117. DOI: 10.1084/jem.20021787.

Herre J., Marshall A.S.J., Caron E., Edwards A.D.,Williams D.L., Schweighoffer E., Tybulewicz V., Reis e Sousa C., Gordon S., Brown G.D. 2004. Dectin-1 utilizes novel mechanisms for yeast phagocytosis in macrophages. Blood 104 (13): 4038-4045. DOI: 10.1182/blood-2004-03-1140.

Hines R.S., Spira D.T. 1974. Ichthyophthiriasis in the mirror carp Cyprinus carpio (L.). V. Acquired immunity. Journal of Fish Biology 6 (4): 373-378.

DOI: 10.1111/j.10958649.1974.tb04554.x.

Lie Ø., Syed M., Solbu H. 1986. Improved agar plate assays of bovine lysozyme and haemolytic complement activity. Acta Veterinaria Scandinavica 27: 23-32.

Manners D.J., Masson A.J., Patterso J.C. 1974. The heterogeneity of glucan preparations from the walls of various yeasts. Journal of General Microbiology 80: 411-417.

Matthews R.A. 2005. Ichthyophthirius multifiliis Fouquet and ichthyophthiriosis in freshwater teleosts. Advances in Parasitology 59: 159-241.

Misra C.K., Das B.K., Mukherjee S.C., Pattnaik P. 2006. Effect of long term administration of dietary $\beta$-glucan on immunity, growth and survival of Labeo rohita fingerlings. Aquaculture 255 (1-4): 82-94. DOI: $10.1016 /$ j.aquaculture.2005.12.009.

Nakao M., Fujiki K., Kondo M., Tomoki Y. 2003. Detection of complement receptors on head kidney phagocytes of the common carp Cyprinus carpio. Fisheries Science 69 (5): 929-935. DOI: 10.1046/j.1444-2906.2003.00709.x.

Paulsen S.M., Engstad R.E., Robertsen B. 2001. Enhanced lysozyme production in Atlantic salmon (Salmo salar L.) macrophages treated with yeast $\beta$-glucan and bacterial lipopolysaccharide. Fish and Shellfish Immunology 11 (1): 23-37. DOI: 10.1006/fsim.2000.0291.

Paulsen S.M., Lunde H., Engstad R E., Robertsen B. 2003. In vivo effects of $\beta$-glucan and LPS on regulation of lysozyme activity and mRNA expression in Atlantic salmon (Salmo salar L.). Fish and Shellfish Immunology 14 (1): 39-54. DOI: $10.1006 /$ fsim.2002.0416.

Pieters N., Brunt J., Austin B., Lyndon A.R. 2008. Efficacy of in-feed probiotics against Aeromonas bestiarum and Ichthyophthirius multifiliis skin infections in rainbow trout (Oncorhynchus mykiss, Walbaum). Journal of Applied 
Microbiology 105 (3): 723-732.

DOI: $10.1111 /$ j.13652672.2008.03817.x.

Sealey W.M., Barrows F.T., Hang A., Johansen K.A., Overturf K., LaPatra S.E., Hardy R.W. 2007. Evaluation of the ability of barley genotypes containing different amounts of $\beta$-glucan to alter growth and disease resistance of rainbow trout Oncorhynchus mykiss. Animal Feed Science and Technology 141 (1-2): 115-128. DOI: 10.1016/j.anifeedsci.2007.05.022.

Selvaraj V., Sampath K., Vaithilingam S. (2006) Adjuvant and immunostimulatory effects of $\beta$-glucan administration in combination with lipopolysaccharide enhances survival and some immune parameters in carp challenged with Aeromonas hydrophila. Veterinary Immunology and Immunopathology 114 (1-2): 15-24.

DOI: $10.1016 /$ j.vetimm.2006.06.011.

Seviour R.J., Stasinopoulos S.J., Auer D.P.F. 1992. Production of pullulan and other exopolysaccharides by filamentous fungi. Critical Reviews in Biotechnology 12: 279-298.

Sigh J., Buchmann K. 2001. Comparison of immobilization assays and enzyme-linked immunosorbent assays for detection of rainbow trout antibody-titres against Ichthyophthirius multifiliis Fouquet, 1876. Journal of Fish Diseases 24 (1): 49-51. DOI: 10.1046/j.1365-2761.2001.00258.x.

Skjermo J., Størseth T.R., Hansen K., Handå A., Øie G. 2006. Evaluation of $\beta$ - $(1 \rightarrow 3,1 \rightarrow 6)$-glucans and High-M alginate used as immunostimulatory dietary supplement during first feeding and weaning of Atlantic cod (Gadus morhua L.) Aquaculture 261 (3): 1088-1101. DOI: 10.1016/j.aquaculture.2006.07.035.

Strand H.K., Dalmo R.A. 1997. Absorption of immunomodulating $\beta(1,3)$-glucan in yolk sac larvae of Atlantic halibut, Hippoglossus hippoglossus (L). Journal of Fish Diseases 20 (1): 41-49. DOI: 10.1046/j.1365-2761.1997.d01-107.x.

Taylor P.R., Brown G.D., Reid D.M., Willment J.A., Martinez-Pomarez L., Gordon S., Wong S.Y.C. 2002. The $\beta$-glucan receptor, dectin- 1 , is predominantly expressed on the surface of cells of the monocyte/macrophage and neutrophil lineages. Journal of Immunology 169: 3876-3882.

Xiao Z., Trincado C.A., Murtaugh M.P. 2004. $\beta$-glucan enhancement of T cell IFN $\gamma$ response in swine. Veterinary Immunology and Immunopathology 102 (3): 315-320. DOI: 10.1016/j.vetimm.2004.09.013.

Xu D.-H., Klesius P.H., Panagala V.S. 2006. Induced crossprotection in channel catfish, Ictalurus punctatus (Rafineque), against different immobilization serotypes of Ichthyophthirius multifiliis. Journal of Fish Diseases 29 (3): 131-138. DOI: 10.1111/j.1365-2761.2006.00700.x.

Zeković D.B., Kwiatkowski S., Vrvić M.M., Jakovljević D., Moran C.A. 2005. Natural and modified ( $\rightarrow 3)$-b-D-glucans in health promotion and disease alleviation. Critical Reviews in Biotechnology 25 (4): 205-230. DOI: 10.1080/07388550500376166.

Received: 2 March 2010

Accepted: 12 April 2010

Published electronically: 25 June 2010 